\title{
Prognostic Value of Graph Theory-Based Tissue Architecture Analysis in Carcinomas of the Tongue
}

\author{
Jon Sudbø, Agnes Bankfalvi, Magne Bryne, Raphael Marcelpoil, Morten Boysen, \\ Joseph Piffko, Jörg Hemmer, Klaus Kraft, and Albrecht Reith
}

Department of Otolaryngology (MBo), The National Hospital, and Department of Oral Biology (MBr), University of Oslo, and Division of Digital Pathology (JS, AR) and Department of Pathology, The Norwegian Radium Hospital, Oslo, Norway; University of Grenoble (RM), Université Joseph Fourier, Grenoble, France; and Department of Cranio-Maxillofacial Surgery (JP), University of Münster, and Gerhard Domagk Institut of Pathology (AB), Münster, and Department of Tumor Biology (JH, KK), University of Ulm, UIm, Germany

\begin{abstract}
SUMMARY: Several studies on oral squamous cell carcinomas (OSCC) suggest that the clinical value of traditional histologic grading is limited both by poor reproducibility and by low prognostic impact. However, the prognostic potential of a strictly quantitative and highly reproducible assessment of the tissue architecture in OSCC has not been evaluated. Using image analysis, in 193 cases of T1-2 (Stage I-II) OSCC we retrospectively investigated the prognostic impact of two graph theory-derived structural features: the average Delaunay Edge Length (DEL_av) and the average homogeneity of the Ulam Tree (ELH_av). Both structural features were derived from subgraphs of the Voronoi Diagram. The geometric centers of the cell nuclei were computed, generating a two-dimensional swarm of point-like seeds from which graphs could be constructed. The impact on survival of the computed values of ELH_av and DEL_av was estimated by the method of Kaplan and Meier, with relapse-free survival and overall survival as end-points. The prognostic values of DEL_av and ELH_av as computed for the invasive front, the superficial part of the carcinoma, the total carcinoma, and the normal-appearing oral mucosa were compared. For DEL_av, significant prognostic information was found in the invasive front $(p<0.001)$. No significant prognostic information was found in superficial part of the carcinoma $(p=0.34)$, in the carcinoma as a whole $(p=0.35)$, or in the normal-appearing mucosa $(p=0.27)$. For ELH_av, significant prognostic information was found in the invasive front $(p=0.01)$ and, surprisingly, in putatively normal mucosa $(p=0.03)$. No significant prognostic information was found in superficial parts of the carcinoma $(p=0.34)$ or in the total carcinoma $(p=0.11)$. In conclusion, strictly quantitative assessment of tissue architecture in the invasive front of OSCC yields highly prognostic information. (Lab Invest 2000, 80:1881-1889).
\end{abstract}

$F$ or a decision instrument to be clinically valuable, by different observers (Wasson et al, 1985). In head and neck cancers, histologic grading is still widely used for reaching a diagnosis, providing a prognosis, and for treatment planning (Pindborg et al, 1997). However, there are large disparities in intraobserver and interobserver grading of oral cancers and precancers, limiting the grading's clinical value (Anneroth et al, 1987; Karabulut et al, 1995; Roland et al, 1992; Stendahl et al, 1980). Despite progress in diagnostic and therapeutic procedures, the long-term survival of oral squamous cell carcinoma (OSCC) patients remains poor (Brunin et al, 1999; Silverman and Gorsky, 1990; Stell et al, 1982). This has prompted the search for better prognostic tools to devise tailored therapies according to the presumed prognoses of individual

Received August 10, 2000.

The work was supported by Grant \#94042/001 from the Norwegian Cancer Society and by a grant from the Research Foundation of the Norwegian Radium Hospital.

Address reprint requests to: Dr. Jon Sudbø, Division of Digital Pathology, Department of Pathology, The Norwegian Radium Hospital, Montebello, 0310 Oslo, Norway.Fax: 47 22935627; E-mail: jon.sudbo@rh.uio.no patients. However, there is a lack of reliable prognostic markers in early stage oral carcinomas (Stell and McCormick, 1985). During the last decade, simplified tumor-grading systems have been introduced, particularly for evaluating the deep invasive margins of carcinomas, demonstrating increased prognostic information (Bryne et al, 1998; Tralongo et al, 1999).

The biological interaction between cells in a tissue probably defines the reciprocal arrangement between cells, perhaps with morphologic manifestations (Bigras et al, 1996; Chandebois, 1977; Heppner, 1993). Furthermore, in vitro transformation studies, eg, in the $\mathrm{C} 3 \mathrm{H} / 10 \mathrm{~T} 1 / 2$ cell line, have demonstrated that adding carcinogens to monolayer fibroblast cultures results in morphologic changes. These changes provide the basis for assaying carcinogens in short-term tests because the morphologic alterations reflect the degree of oncogenic transformation (Reznikoff et al, 1983; Saxholm, 1984). The morphologic manifestations of cellular interactions in tissues may be given a quantitative expression by employing graphs such as the Voronoi Diagram (VD) and its subgraphs (Fig. 1A) (Kayser and Stute, 1989). In carcinomas of the prostate, the computed weighted sum of a minimal 
A

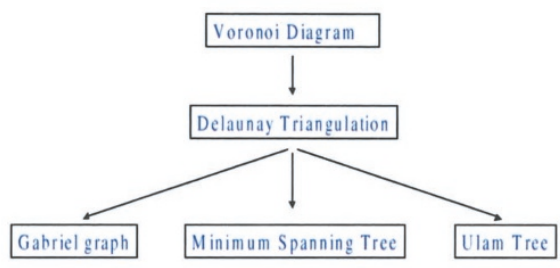

$\mathrm{C}$

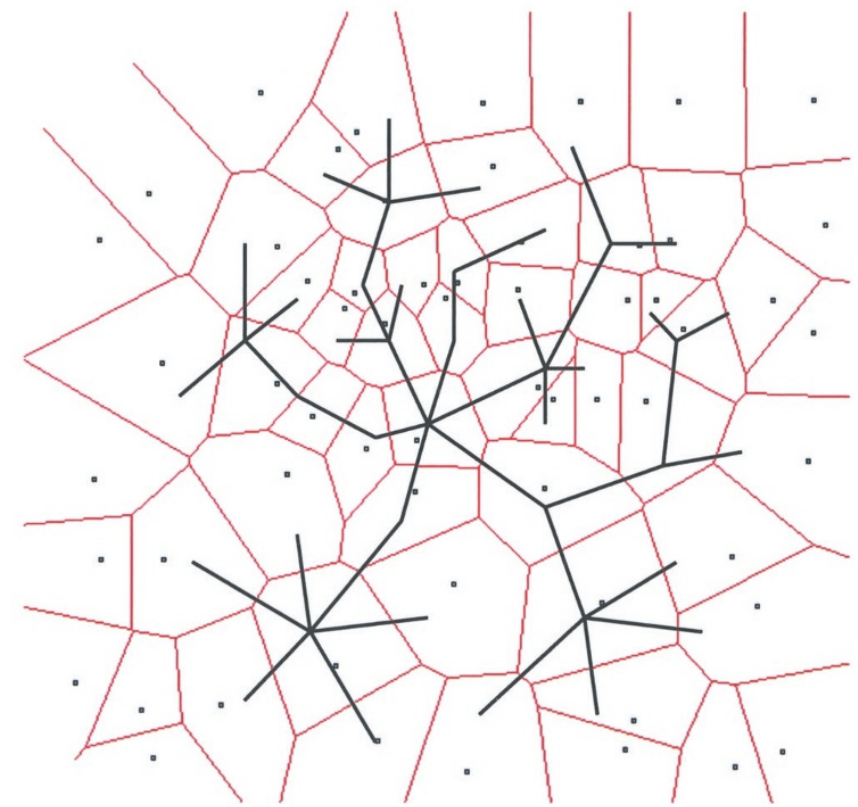

B

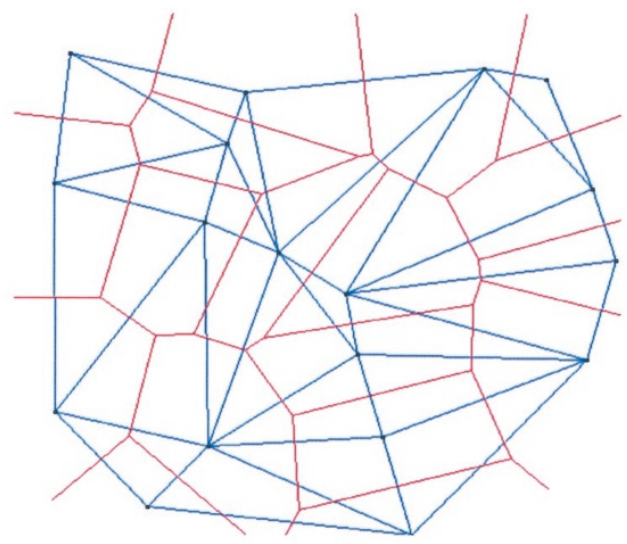

Figure 1.

$A$, The main graphs that can be derived from the Voronoi Diagram (VD). In this study, the Delaunay Triangulation (DT) was used to generate the structural feature DEL_av, the average Delaunay Edge Length, and the Ulam Tree (UT) was used to generate the structural feature ELH_av, the average homogeneity of the Ulam Tree. $B$, The relationship between the Voronoi polygons (red) and the DT (blue). The summit of the neighboring DT (arrows in $B$ ) corresponds to the geometric center of each Voronoi polygon. The entire set of Voronoi polygons makes up the VD. C, The UT.

spanning tree structure correlates well with Gleason grading of the carcinomas, indicating a possible prognostic value of this graph theory-based structural feature (Wetzel et al, 1997). In a pilot study, we developed and tested a number of VD-derived structural features and applied them to data from 8 cases of carcinomas of the tongue, 30 cases (15 with a good and 15 with a poor outcome) of carcinoma of the prostate, and 10 cases of carcinomas of the cervix (Sudbø J et al, 2000). In this pilot study, two structural features, the average Delaunay Edge Length (DEL_av) and the average homogeneity of the Ulam Tree (ELH_av) were found to have a prognostic impact.

The present study investigated the prognostic value of the structural features DEL_av and ELH_av in 193 cases of OSCC (30 in a learning set and 163 in an independent test set, Table 1). In keeping with findings from previously published semiquantitative studies (Bryne et al, 1998; Piffko et al, 1997a), the present study included a separate analysis of tissue architecture in the invasive front of the carcinomas.

\section{Results}

\section{Main Findings}

Graph theory-based quantitation of tissue architecture produced significant prognostic information in OSCC, particularly from the deep, invasive parts of the carcinomas.

\section{Reproducibility in Repeated Computations}

Using the methods derived from graph theory, assessment of tissue architecture was highly reproducible. In ten separate computations on 5000 cells, repeated quantitation of tissue architecture for the structural features DEL_av and ELH_av were highly reproducible, with respective coefficients of variation of $1.78 \%$ and $1.96 \%$ (Table 2). The co-variation in the computations of ELH_av and DEL_av was also assessed by the least square regression analysis, and was acceptable ( $R^{2} 0.85$ to 0.91 in ten consecutive computations, data not shown). 
Table 1. Clinical Outcome of 193 Treated Cases of OSCC Stage T1-2

\begin{tabular}{|c|c|}
\hline \multicolumn{2}{|c|}{ A. Total population $(n=193)$} \\
\hline Clinical outcome & $\begin{array}{c}\text { Number of } \\
\text { patients }\end{array}$ \\
\hline \multicolumn{2}{|l|}{ Treatment failure } \\
\hline Residual disease & $36(19 \%)$ \\
\hline Local recurrence & $29(15 \%)$ \\
\hline Regional recurrence & 37 (19\%) \\
\hline Distant metastasis & $22(11 \%)$ \\
\hline Relapse-free survival & $69(36 \%)$ \\
\hline Total & $193(100 \%)$ \\
\hline \multicolumn{2}{|l|}{ B. Learning set $(n=30)$} \\
\hline Clinical outcome & $\begin{array}{c}\text { Number of } \\
\text { patients }\end{array}$ \\
\hline $\begin{array}{l}\text { Relapse-free survival } \\
\quad>10 \text { years }\end{array}$ & $15(50 \%)$ \\
\hline $\begin{array}{l}\text { Relapse-free survival } \\
\quad<3 \text { years }\end{array}$ & $15(50 \%)$ \\
\hline Total & $30(100 \%)$ \\
\hline \multicolumn{2}{|c|}{ C. Independent test set $(n=163)$} \\
\hline Clinical outcome & $\begin{array}{l}\text { Number of } \\
\text { patients }\end{array}$ \\
\hline \multicolumn{2}{|l|}{ Treatment failure } \\
\hline Residual disease & $31(19 \%)$ \\
\hline Local recurrence & $24(15 \%)$ \\
\hline Regional recurrence & $33(20 \%)$ \\
\hline Distant metastasis & $21(13 \%)$ \\
\hline Relapse-free survival & $54(33 \%)$ \\
\hline Total & $163(100 \%)$ \\
\hline
\end{tabular}

OSCC, oral squamous cell carcinoma.

Table 2. Reproducibility in the Value of a Structural Feature in 10 Consecutive Computations of 2 Structural Features $^{a}$

\begin{tabular}{cc}
\hline DEL_av (CV = 1.78\%) & ELH_av (CV = 1.96\%) \\
\hline 29.10 & 0.61 \\
29.12 & 0.60 \\
28.90 & 0.58 \\
29.14 & 0.59 \\
29.60 & 0.61 \\
29.17 & 0.57 \\
29.01 & 0.59 \\
28.77 & 0.57 \\
29.13 & 0.63 \\
29.46 & 0.60 \\
\hline
\end{tabular}

CV, coefficient of variation.

a 10,000 cells were analyzed.

\section{Morphologic Discrimination Between Different Anatomical Compartments}

The tissue architecture properties were compared in the invasive front, the superficial part of the carci- noma, and the putatively normal oral mucosa adjacent to the bulk of the carcinoma by combining the two structural features ELH_av (first discriminant function) and DEL_av (second discriminant function). Using this model on an independent test set of 89 cases we were able to distinguish between three separate anatomical compartments related to the carcinoma (Fig. 2). On the basis of this model, we were able to correctly classify the histologic properties in $95 \%(85 / 89)$ of the normal tissue samples, in $84 \%(75 / 89)$ of the superficial samples, and in $94 \%(85 / 89)$ of the invasive front samples.

\section{Prognosis in Learning Set of 30 Cases of OSCC}

Fifteen cases of good prognosis (relapse-free survival for more than 10 years) and 15 cases of poor prognosis (relapse within three years of initial treatment) were compared for the structural features ELH_av and DEL_av with respect to relapse-free and overall survival (Fig. 3). Both structural features extracted significant prognostic information from the invasive front in this learning set of two clear-cut outcome groups $(p<$ 0.001). Similar results were seen from additional computations in four other cases. The survival curves for the two structural features were identical, indicating that the two structural features allocated the same patients to the favorable and poor prognosis groups.

\section{Prognosis in an Independent Test Set of 163 Cases of OSCC}

Having confirmed that the two structural features were prognostically significant in a learning set of 30 cases of OSCC, an independent test set of 163 cases of OSCC (Table 3) were analyzed in a blinded fashion and separated into two distinct groups according to value of the structural features. The prognostic information was then assessed according to the method of Kaplan-Meier (Fig. 4). For DEL_av, significant prognostic information was found in the invasive front $(p<$ 0.001). No significant prognostic information was found in superficial part of the carcinomas $(p=0.34)$, in putatively normal oral mucosa adjacent to the bulk of the carcinomas $(p=0.27)$, or the bulk of the carcinomas (both the invasive front and the more superficial parts of the tumor) ( $p=0.35$; survival curves not shown). For ELH_av, significant prognostic information was found in the invasive front $(p=0.01)$ and, surprisingly, in adjacent normal-appearing mu$\operatorname{cosa}(p=0.03)$. No significant prognostic information was found in superficial parts of the carcinomas $(p=$ $0.34)$ or in the bulk of the carcinomas $(p=0.11)$.

\section{Discussion}

Given the increasing incidence of OSCC in younger persons (Atula et al, 1996; Friedlander et al, 1998; Myers et al, 2000) and the current poor long-term survival of OSCC (Silverman and Gorsky, 1990), there 


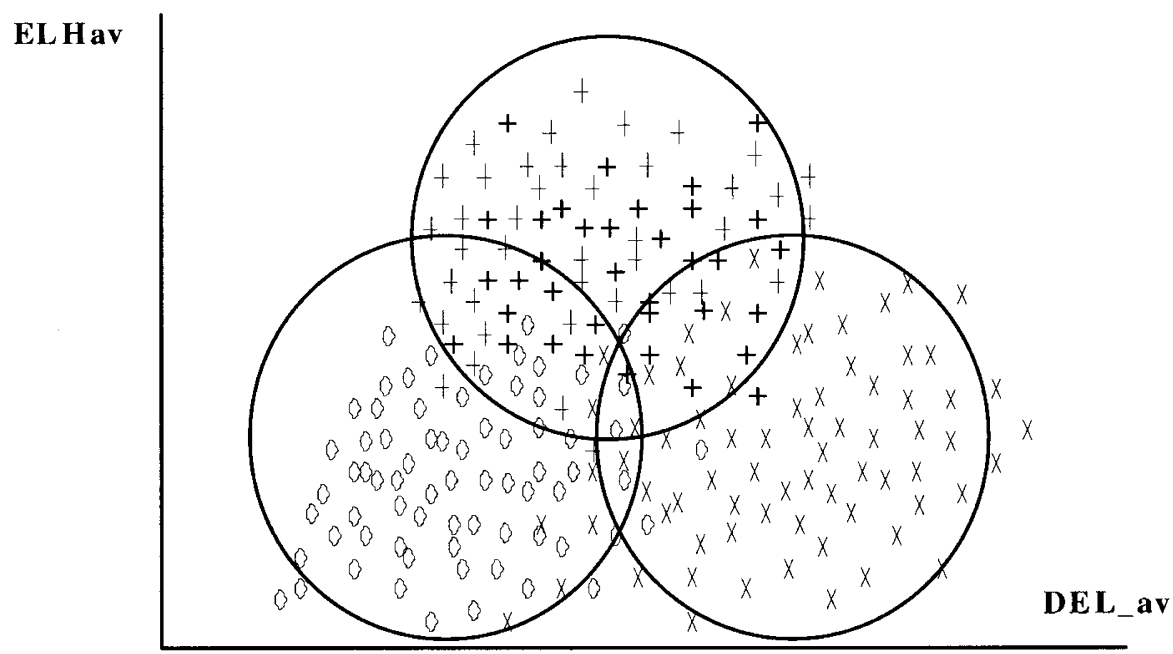

Figure 2.

Differentiation in three anatomical subdivisions in OSCC biopsies using the structural features ELH_av and DEL_av as discriminant functions.

A

\section{ELH_av}

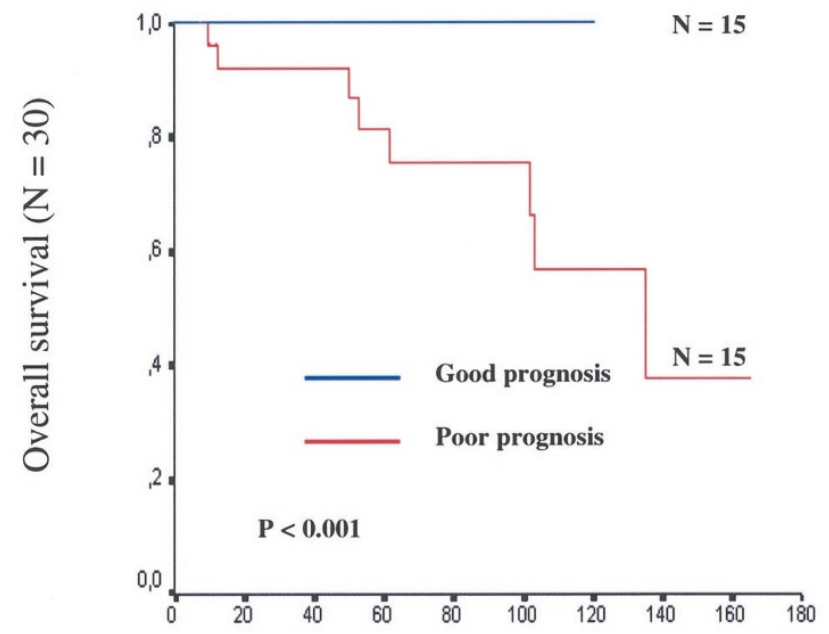

B

DEL_av

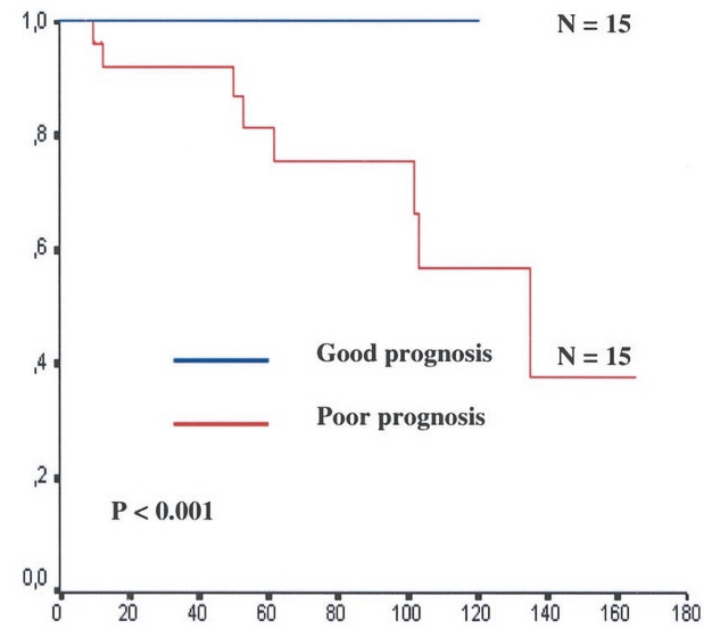

Survival time in months

Figure 3.

Kaplan-Meier estimates (overall survival curves) for the learning set of 30 carcinomas, 15 with clearly favorable prognoses (relapse-free survival more than 10 years) and 15 with clearly unfavorable prognoses (relapse within 3 years after initial treatment). $A$, Survival curves for the structural feature ELH_av. $B$, The corresponding curves for DEL_av. Note that the curves are identical, indicating that both structural features have assigned the same cases to the favorable and unfavorable prognosis groups.

is a need for establishing reliable prognostic markers in malignant lesions of the oral cavity. When searching for such prognostic markers, it has become increasingly evident that tumor heterogeneity must be considered (Diaz-Cano et al, 2000; El-Naggar et al, 1995;
Partridge et al, 1999; Piffko et al, 1997b; Sanders et al, 1998). The prognostic importance of the invasive front of carcinomas has become a focus of interest, as shown by semiquantitative studies that have examined tumor size, depth of invasion, and histologic 
Table 3. Characteristics of Study Patients

\begin{tabular}{lcc}
\hline \multicolumn{1}{c}{ Characteristics } & Good prognosis group $(n=95)$ & Poor prognosis group $(n=89)$ \\
\hline Mean age (yr) & 68.5 & 69.7 \\
Male sex (\%) & 65 & 67 \\
Stage (\%) & 52 & 46 \\
T1 & 48 & 54 \\
T2 & 78 & 81 \\
Previously diagnosed leukoplakia (\%) & & 49 \\
Location of carcinoma (\%) & 57 & 51 \\
Lateral border of tongue & 43 & \\
Lateral border and floor of the mouth & & \\
\hline
\end{tabular}

grading of the invasive front (Bryne et al, 1998), and also correlated the effect of chemotherapy to the mode of invasion (Yamamoto et al, 1983). Tumor morphology in the invasive front of a carcinoma often differs from more superficial parts of the tumor, with less differentiation of cells and a higher cellular dissociation. In carcinomas, clonal expansion and progression of stem lines result in heterogeneously composed tumors, consisting of subdivisions that have different aggressiveness in the growth pattern towards neighboring tissues (Heppner, 1993; Heppner and Miller, 1998).

Based on the assumption that tumor biology somehow finds a morphologic expression, there are compelling reasons to assume that the invasive front of a carcinoma should contain morphologic information of particular clinical importance (Bryne et al, 1991, 1998; Piffko et al, 1997a). In the present paper, we demonstrate that, in particular, the invasive front of OSCC contains morphologic information with high prognostic value. The results in the present study are consistent with our previous findings in a pilot study, in which we found that graph theory-based quantitation of tissue architecture was well suited for prognostication of several types of carcinomas (Sudbø et al, 2000).

Interestingly, a prognostic value was found for the structural feature ELH_av in putative normal oral mucosa. This indicates that there is morphologic information not detected by the human eye that may contain prognostic information. In several tissues, nuclear differences have been described in normalappearing cells from patients with invasive carcinomas, and the concept of malignancy-associated changes as prognostic markers in invasive and preinvasive cancers has been investigated (Bibbo et al, 1989; Ikeda et al, 1998; MacAulay et al, 1995; Mairinger et al, 1999; Susnik et al, 1995). However, to our knowledge, our findings are the first to describe such possible changes on a level of tissue architecture.

For a given set of possible but not established prognostic markers, re-substitution of cases in a data set and cross-validation of classification performance tends to give overly optimistic results (Schulerud et al, 1998). Over-fitting (the structural features give a good characterization of the class in the specific learning set but not in the general population of cases to be investigated) may occur if the number of patients in the smallest outcome group is very different from that in the largest group, or if the number of structural features is large compared with the number of cases investigated. Therefore, possible prognostic markers must be established on a learning set where the number of cases is significantly larger than the number of features selected. Furthermore, statistical evaluation of the classification performance of a set of selected structural features must be obtained on an independent data set before valid conclusions may be drawn. Accordingly, in the present study, 30 cases (15 with clearly favorable and 15 with clearly poor clinical outcome) of a total of 193 cases were used to establish the two structural features (DEL_av and ELH_av) as possible prognostic morphologic markers in OSCC. We thereafter evaluated the classification performance of these two structural features on an independent test set of 163 cases of OSCC (78 with favorable and 85 with poor prognosis). The reproduction in an independent test set of the prognostic results found in the learning set gives credit to the results in the present study.

Carcinomas of the head and neck continues to have a poor prognosis, despite introduction of new therapeutic modalities (Charabi et al, 1997; Hicks et al, 1997; Jacobs et al, 1990; Martis, 1982; Stell and McCormick, 1985; Sun et al, 1997). The need for improved diagnostics is therefore obvious, and texture analysis on tissues is one possible approach.

Ultimately, the impact of graph theory-based prognostic methods on the morbidity and mortality of OSCC must be ascertained from a prospective trial in with patients randomized to different treatment groups according to prognostic information derived from structural features. However, to the best of our knowledge, the present study represents the first effort using a fairly large clinical material set, in which it is unequivocally demonstrated that a highly reproducible and strictly quantitative assessment of tissue architecture contains morphologic information of significant prognostic value.

\section{Materials and Methods}

\section{Clinical Material}

Five- to seven-micron-thick tissue sections from radical operations performed between January 1, 1985 
ELH_av
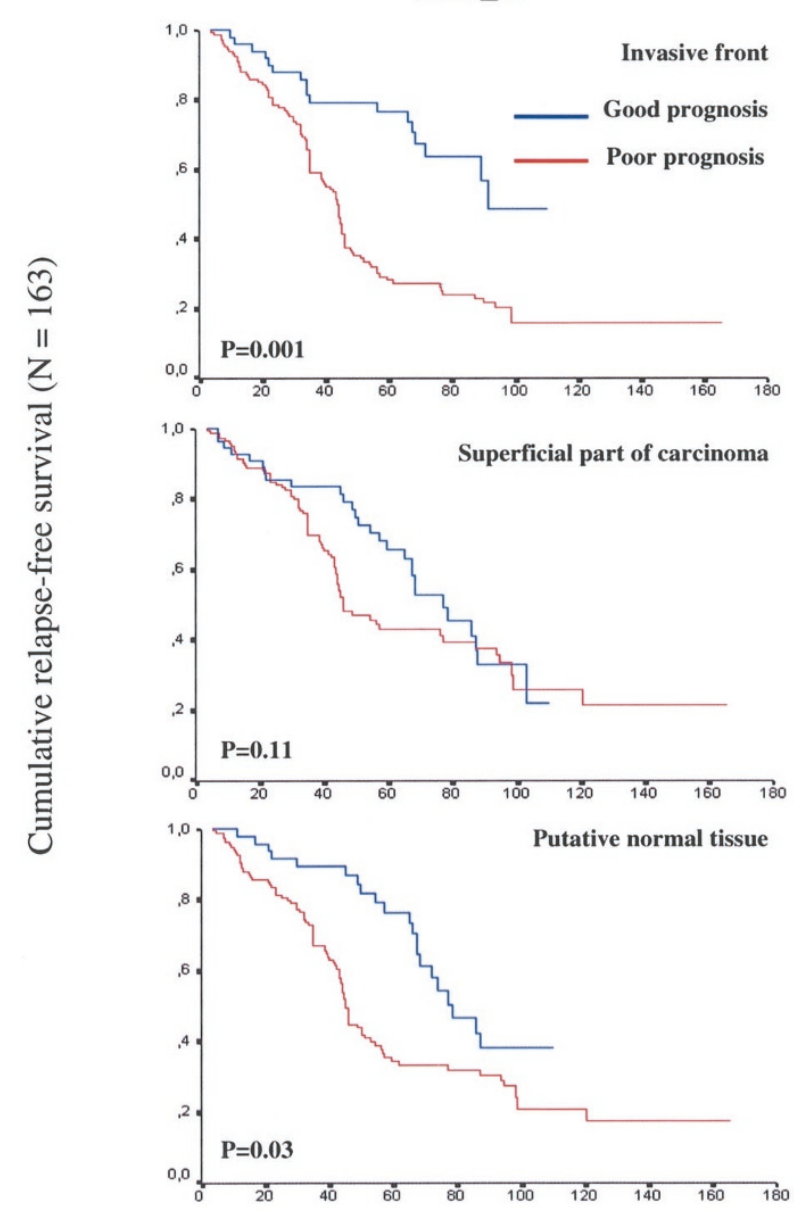

DEL_av
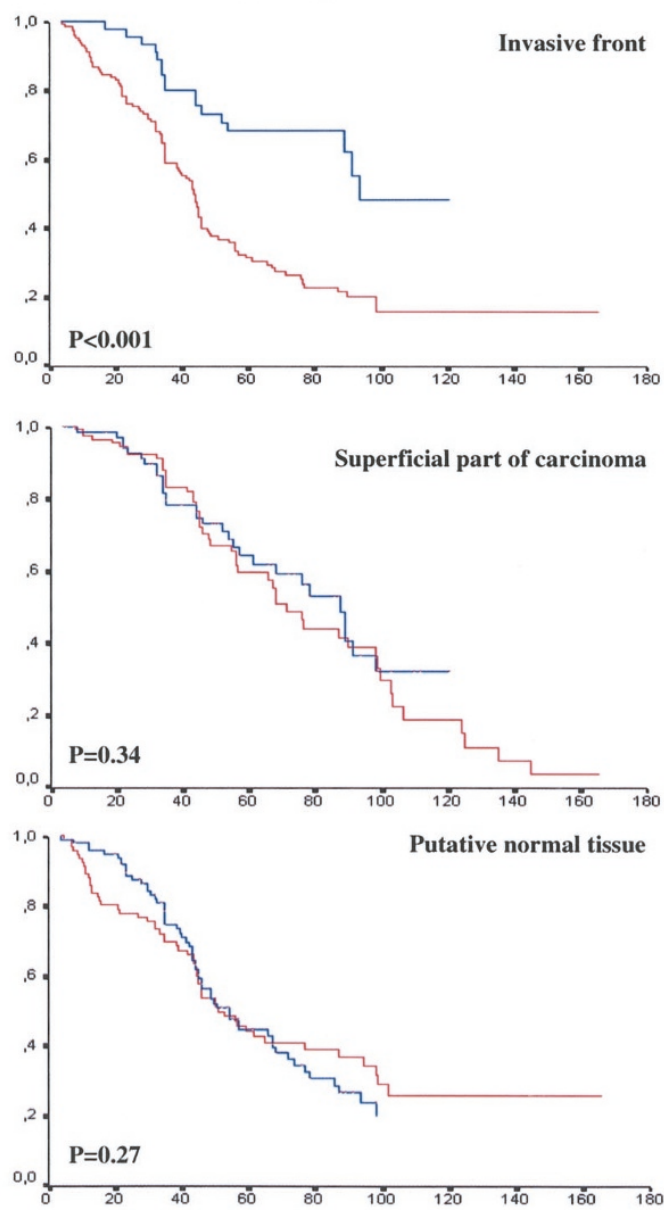

Survival time in months

Figure 4.

Survival curves for ELH_av and DEL_av. For both structural features, significant prognostic information is demonstrated in the invasive front of the carcinomas. Interestingly, for the structural feature ELH_av, significant prognostic information was also contained in the putatively normal oral mucosa adjacent to the carcinomas.

and December 31, 1994 of 193 retrospectively investigated cases of T1-2 squamous cell carcinoma of the tongue were obtained from the Gerhard Domagk Institute of Pathology, Münster, Germany and the Department of Pathology, University of UIm, Germany. All lesions were initially staged according to the pTNM of the International Union Against Cancer (1992). The mean time of follow-up was 66 months (range 16 to 167 months). All patients were irradiated postoperatively according to appropriate protocols. There were 124 patients with treatment failure; residual disease $(n$ $=36$ ), local recurrence $(n=29)$, regional recurrence ( $n$ = 37), and distant metastasis $(n=22)$ (Table 1). Sixty-nine patients were alive with no relapse 5 years after initial treatment. The areas defined as carcinomas were defined by two independent pathologists in sections stained with hematoxylin and eosin. For all 193 cases, areas of mucosa that were not defined as carcinomatous could be found adjacent to the carcinomas. These areas were classified as putatively normal oral mucosa. Characteristics of the patients are given in Table 3.

\section{Tissue Staining}

To eliminate the background staining of the cytoplasm, we used the Feulgen-Schiff reaction, which selectively stains aldehyde groups in the nuclear DNA with very sparse staining of the cytoplasm. The Feulgen-Schiff staining procedure was modified by a postfixation in $4 \%$ formaldehyde before treating the sections with $5 \mathrm{M} \mathrm{HCl}$ at room temperature $\left(22^{\circ} \mathrm{C}\right)$. A trained pathologist (B. Risberg, A.B.) selected areas relevant for analysis from adjacent sections stained with hematoxylin and eosin.

\section{Data Acquisition}

Gray level images were digitized using a Single Chip digital camera (C4742-95; Hamamatsu Photonics Hamamatsu, Japan) with high resolution. The camera was mounted on a Leica DM-LB microscope $(\times 40$ / $0.65 \infty=0.17)$, modified for computer control of the stage (Prior HI52V2; Prior Scientific Instruments, Cambridge, United Kingdom), and equipped with a trinocu- 
lar head to allow images to be focused on the pixel elements of the high resolution digital camera. The final magnification was $\times 400$ at an estimated resolution of $680 \mathrm{~nm}$ (0.7 micrometers) per pixel, $1024 \times$ 1024 pixels with 10-bit resolution (1024 grey levels) per visual field. The microscope stage was manually directed to acquire the desired area of analysis. The PathSight Version 3.0 software (Second Opinion Solutions, Oslo, Norway) was used to obtain monochrome images for analysis. Alignment of the fields of view relied on the mechanical precision of the microscope stage. After compiling 36 to 81 fields of view, areas of interest were digitally defined as closed contours using a previously described algorithm (Sudbø et al, 2000). Only cellular elements within the digitally defined areas were included in the computations (Fig. 5).

\section{Data Analysis}

The values of two structural features were computed, based on previous findings (Sudbø et al, 2000). From graphs such as the VD, subgraphs can be con- structed. From these graphs, a number of structural features may be computed that quantitatively describe different aspects of the tissue architecture (Sudbø et al, 2000).

\section{Reproducibility in Repeated Computations of Structural Features}

For assessing the reproducibility in the computations of the structural features, 10 consecutive computations were obtained from four different slides. Between computations, the slides were removed from the microscope stage and the computer and microscope were turned off.

\section{Learning Set for Prognostic Evaluation}

Thirty cases of OSCC were used as a learning set, 15 with known good prognosis (relapse-free survival more than 10 years) and 15 with known poor prognosis (relapse within three years of initial treatment). After computing the values of the two structural features in the learning set, the mean values and $95 \%$ confidence
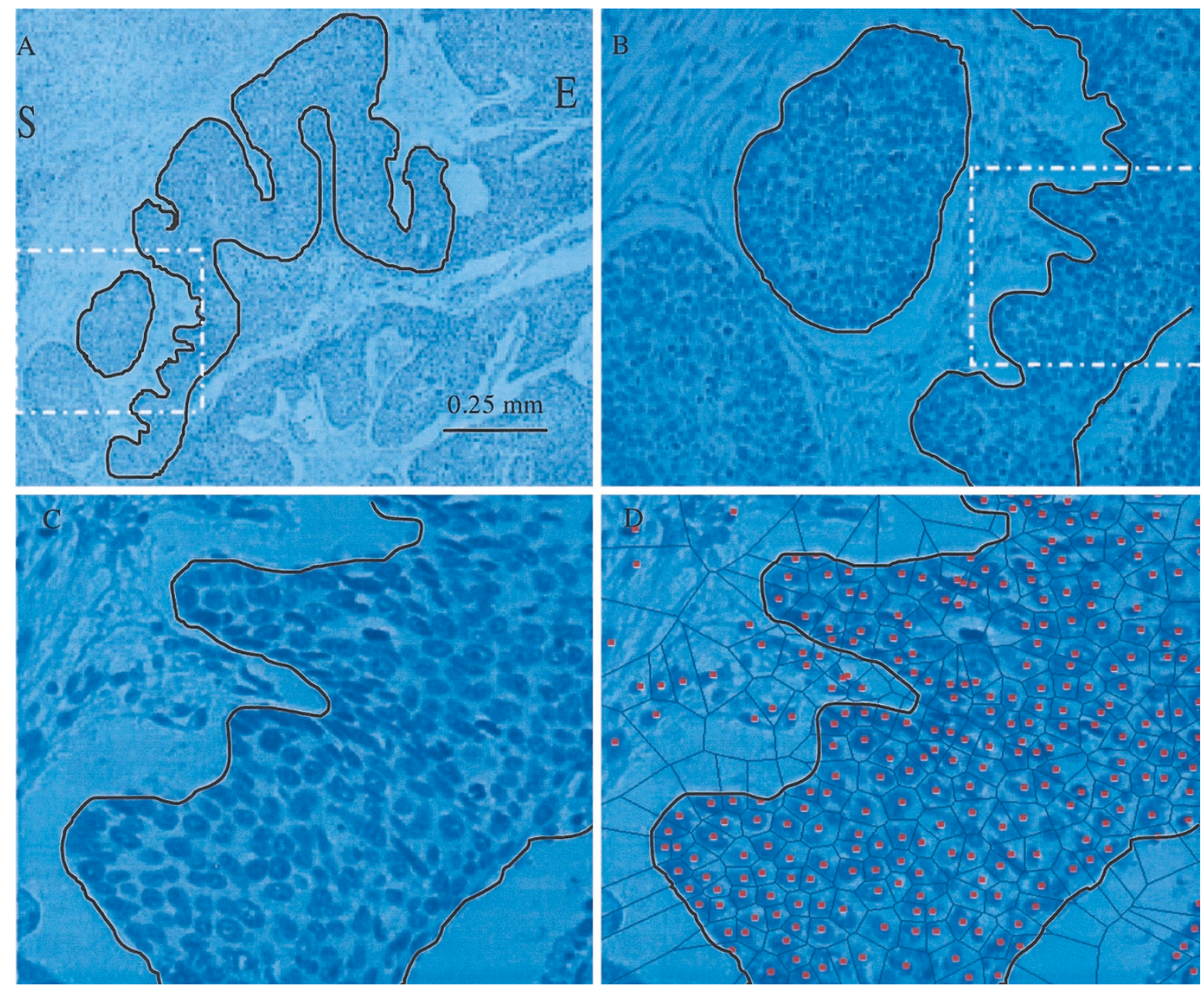

Figure 5.

Space partitioning of tissue sections for architectural analysis. $A$, Selected area of interest (36 fields of view) with windows of analysis defined by the closed contours (black lines). B, Detail, corresponding to the delineated square in $A$. C, Detail from an area to be analyzed, with the tissue partitioned according to the Voronoi Diagram (VD) in $D$. The areas of interest (inside the closed contours defined by the black lines) were digitally defined according to a previously developed algorithm. 
Table 4. Computation of the Structural Features, ELH_av and DEL_av, from a Learning Set of 30 Cases of OSCC, 15 with Good and 15 with Poor Prognoses

\begin{tabular}{lccc}
\hline & \multicolumn{3}{c}{ Mean values $(95 \%$ confidence intervals $)$} \\
\cline { 2 - 4 } Structural feature & Good prognosis $(n=15)$ & Carcinoma of the tongue $(n=15)$ & $p$-value Student's t-test \\
\hline DEL_av & 27.3 & 26.1 & 0.01 \\
ELH_av & $(25.9-27.3)$ & $(25.2-26.7)$ & 0.30 \\
& 0.43 & $(0.24-0.41)$ & 0.01 \\
\hline
\end{tabular}

interval $(\mathrm{Cl})$ were computed for each of the outcome groups. In the test set, the cut-off for inclusion in the good prognosis group according to the structural feature ELH_av was set at the lower limit of the $95 \% \mathrm{Cl}$ for the good prognosis group as computed in the learning set (Table 4). The other cases were allocated to the poor prognosis group. For the structural feature DEL_av, the cut-off for inclusion in the good prognosis group was set at the lower limit of the $95 \% \mathrm{Cl}$ and at the upper limit of the $95 \% \mathrm{Cl}$ for the good prognosis group as computed in the learning set. The other cases were allocated to the poor prognosis group.

\section{Test Set for Prognostic Evaluation}

The test set was derived from the residual 163 cases. None of the 30 cases used in the learning set was included in the independent test set. Generally, differences with respect to clinical outcome were not as clear-cut in the test set as in the learning set.

\section{Discriminant Analysis}

Tissue architectural properties in different anatomical compartments related to the carcinomas were investigated by the use of discriminant analysis (Lachenbruch, 1975). The structural feature ELH_av was included as the first discriminant function and DEL_av as the second discriminant function. Tissue architecture analysis was performed on the invasive front, the superficial part of the carcinoma, and the normalappearing oral mucosa adjacent to the bulk of the carcinoma. From a learning set of 30 randomly chosen cases, a model was constructed for expected values in the superficial part of the carcinoma and for the normal-appearing oral mucosa adjacent to the bulk of the carcinoma. This model was applied to an independent test set of 89 cases OSCC (Fig. 2).

\section{Statistical Analysis}

Statistical analysis was performed using SPSS 9.0 for Windows (SPSS Inc., Chicago, Illinois, 1999). Reproducibility in the computations of both ELH_av and DEL_av was assessed by least square regression analysis $\left(R^{2}\right)$. The two means were compared using Student's nonparametric $t$ test. Kaplan-Meier estimates were used to assess the prognostic value of DEL_av and ELH_av with respect to relapse-free and overall survival. Cases were censored if death resulted from unrelated disease. In a discriminant analysis, we used ELH_av as the first discriminant function and DEL_av the second discriminant function. All $p$-values were two-sided and $p$-values $<0.05$ were regarded as statistically significant.

\section{Acknowledgements}

The authors are indebted to Ms. Ruth Punthervold and Ms. Marna Lill Kjæreng for excellent technical assistance in preparing high quality Feulgen-stained sections. Discussions with Professor Eva Skovlund about the statistical analysis are acknowledged.

\section{References}

Anneroth G, Batsakis J, and Luna M (1987). Review of the literature and a recommended system of malignancy grading in oral squamous cell carcinomas. Scand J Dent Res 95:229-249.

Atula S, Grenman R, Laippala P, and Syrjanen S (1996). Cancer of the tongue in patients younger than 40 years. A distinct entity? Arch Otolaryngol Head Neck Surg 122:13131319.

Bibbo M, Montag AG, Lerma-Puertas E, Dytch HE, Leelakusolvong S, and Bartels PH (1989). Karyometric marker features in tissue adjacent to invasive cervical carcinomas. Anal Quant Cytol Histol 11:281-285.

Bigras G, Marcelpoil R, Brambilla E, and Brugal G (1996). Cellular sociology applied to neuroendocrine tumors of the lung: Quantitative model of neoplastic architecture. Cytometry $24: 74-82$.

Brunin F, Mosseri V, Jaulerry C, Point D, Cosset JM, and Rodriguez J (1999). Cancer of the base of the tongue: Past and future. Head Neck 21:751-759.

Bryne M, Boysen M, Alfsen CG, Abeler VM, Sudbo J, Nesland JM, Kristensen GB, Piffko J, and Bankfalvi A (1998). The invasive front of carcinomas. The most important area for tumour prognosis? Anticancer Res 18:4757-4764.

Bryne M, Thrane PS, and Dabelsteen E (1991). Loss of expression of blood group antigen $\mathrm{H}$ is associated with cellular invasion and spread of oral squamous cell carcinomas. Cancer 67:613-618.

Chandebois R (1977). Cell sociology and the problem of position effect: Pattern formation, origin and role of gradients. Acta Biotheor 26:203-238.

Charabi S, Balle V, Charabi B, Berthelsen A, and Thomsen J (1997). Squamous cell carcinoma of the oral cavity: The results of the surgical and non-surgical therapeutic modalities in a consecutive series of 156 patients treated in Copenhagen county. Acta Otolaryngol Suppl 529:226-228. 
Diaz-Cano SJ, Blanes A, Rubio J, Matilla A, and Wolfe HJ (2000). Molecular evolution and intratumor heterogeneity by topographic compartments in muscle-invasive transitional cell carcinoma of the urinary bladder. Lab Invest 80:279-289.

El-Naggar AK, Steck K, and Batsakis JG (1995). Heterogeneity of the proliferative fraction and cyclin D1/CCND1 gene amplification in head and neck squamous cell carcinoma. Cytometry 21:47-51.

Friedlander PL, Schantz SP, Shaha AR, Yu G, and Shah JP (1998). Squamous cell carcinoma of the tongue in young patients: A matched-pair analysis. Head Neck 20:363-368.

Heppner GH (1993). Cancer cell societies and tumor progression. Stem Cells 11:199-203.

Heppner GH and Miller FR (1998). The cellular basis of tumor progression. Int Rev Cytol 177:1-56.

Hicks WLJ, Loree TR, Garcia RI, Maamoun S, Marshall D, Orner JB, Bakamjian VY, and Shedd DP (1997). Squamous cell carcinoma of the floor of mouth: A 20 -year review. Head Neck 19:400-405.

Ikeda N, MacAulay C, Lam S, LeRiche J, Payne P, Garner D, Konaka C, Kato H, and Palcic B (1998). Malignancy associated changes in bronchial epithelial cells and clinical application as a biomarker. Lung Cancer 19:161-166.

Jacobs CD, Goffinet DR, and Fee WEJ (1990). Head and neck squamous cancers. Curr Probl Cancer 14:1-72.

Karabulut A, Reibel J, Therkildsen MH, Praetorius F, Nielsen HW, and Dabelsteen E (1995). Observer variability in the histologic assessment of oral premalignant lesions. J Oral Pathol Med 24:198-200.

Kayser K and Stute H (1989). Minimum spanning tree, Voronoi's tessellation and Johnson-Mehl diagrams in human lung carcinoma. Pathol Res Pract 185:729-734.

Lachenbruch PA (1975). Discriminant Analysis. New York: Hafner Press.

MacAulay C, Lam S, Payne PW, LeRiche JC, and Palcic B (1995). Malignancy-associated changes in bronchial epithelial cells in biopsy specimens. Anal Quant Cytol Histol 17:55-61.

Mairinger T, Mikuz G, and Gschwendtner A (1999). Nuclear chromatin texture analysis of nonmalignant tissue can detect adjacent prostatic adenocarcinoma. Prostate 41:12-19.

Martis CS (1982). Carcinoma of the tongue: Evaluation of surgical treatment of 123 cases. J Oral Maxillofac Surg 40:340-347.

Myers JN, Elkins T, Roberts D, and Byers RM (2000). Squamous cell carcinoma of the tongue in young adults: Increasing incidence and factors that predict treatment outcomes. Otolaryngol Head Neck Surg 122:44-51.

Partridge M, Emilion G, Falworth M, A'Hern R, Phillips E, Pateromichelakis S, and Langdon J (1999). Patient-specific mutation databases for oral cancer. Int J Cancer 84:284-292.

Piffko J, Bankfalvi A, Ofner D, Bryne M, Rasch D, Joos U, Bocker W, and Schmid KW (1997a). Prognostic value of histobiological factors (malignancy grading and AgNOR content) assessed at the invasive tumour front of oral squamous cell carcinomas. Br J Cancer 75:1543-1546.

Piffko J, Bankfalvi A, Ofner D, Rasch D, Joos U, and Schmid KW (1997b). Standardized AgNOR analysis of the invasive tumour front in oral squamous cell carcinomas. J Pathol 182:450-456.
Pindborg JJ, Reichart PA, Smith CJ, and van der Waal J, editors (1997). Histological typing of cancer and precancer of the oral mucosa, 2nd ed. London: Springer, 21-26.

Reznikoff CA, Gilchrist KW, Norback DH, Cummings KB, Erturk E, and Bryan GT (1983). Altered growth patterns in vitro of human papillary transitional carcinoma cells. Am J Pathol 111:263-272.

Roland NJ, Caslin AW, Nash J, and Stell PM (1992). Value of grading squamous cell carcinoma of the head and neck. Head Neck 14:224-229.

Sanders DS, Bruton R, Darnton SJ, Casson AG, Hanson I, Williams HK, and Jankowski J (1998). Sequential changes in cadherin-catenin expression associated with the progression and heterogeneity of primary oesophageal squamous carcinoma [published erratum appears in Int $\mathrm{J}$ Cancer 84:336]. Int J Cancer 79:573-579.

Saxholm HJ (1984). Effects of nickel compounds in cell culture. IARC Sci Publ 165-174.

Schulerud H, Kristensen GB, Liestol K, Vlatkovic L, Reith A, Albregtsen F, and Danielsen HE (1998). A review of caveats in statistical nuclear image analysis. Anal Cell Pathol 16:63-82.

Silverman SJ and Gorsky M (1990). Epidemiologic and demographic update in oral cancer: California and national data - 1973 to 1985. J Am Dent Assoc 120:495-499.

Stell PM and McCormick MS (1985). Cancer of the head and neck: Are we doing any better? (Letter). Lancet 2:1127.

Stell PM, Wood GD, and Scott MH (1982). Early oral cancer: Treatment by biopsy excision. Br J Oral Surg 20:234-238.

Stendahl U, Willen H, and Willen R (1980). Invasive squamous cell carcinoma of the uterine cervix. I. Definition of parameters in a histopathologic malignancy grading system. Acta Radiol Oncol 19:467-480.

Sudbø J, Marcelpoil R, and Reith A (In press, 2000). New algorithms based on the Voronoi Diagram applied in a pilot study on normal mucosa and carcinomas. Anal Cell Pathol.

Sun LM, Leung SW, Su CY, and Wang CJ (1997). The relapse patterns and outcome of postoperative recurrent tongue cancer. J Oral Maxillofac Surg 55:827-831.

Susnik B, Worth A, LeRiche J, and Palcic B (1995). Malignancy-associated changes in the breast. Changes in chromatin distribution in epithelial cells in normal-appearing tissue adjacent to carcinoma. Anal Quant Cytol Histol 17:62-68.

Tralongo V, Rodolico V, Luciani A, Marra G, and Daniele E (1999). Prognostic factors in oral squamous cell carcinoma. A review of the literature. Anticancer Res 19:3503-3510.

Wasson JH, Sox HC, Neff RK, and Goldman L (1985). Clinical prediction rules. Applications and methodological standards. N Engl J Med 313:793-799.

Wetzel AW, Andrews PL, Becich MJ, and Gilbertson J (1997). Computational aspects of pathology image classification and retrieval. J Supercomputing 11:279-293.

Yamamoto E, Kohama G, Sunakawa H, Iwai M, and Hiratsuka $H$ (1983). Mode of invasion, bleomycin sensitivity, and clinical course in squamous cell carcinoma of the oral cavity. Cancer 51:2175-2180. 